\title{
A Visão da Academia e do Mercado de Trabalho sobre o Ensino da Auditoria
}

\begin{abstract}
Resumo
O objetivo deste trabalho foi identificar a percepção do ensino de auditoria sob o enfoque da academia e do mercado de trabalho, com base na avaliação da importância dada por profissionais e docentes aos principais aspectos conceituais e normativos da área de auditoria. Para alcançar o objetivo proposto, coletou-se a percepção dos docentes responsáveis pela disciplina de auditoria e dos auditores atuantes no mercado de trabalho por meio de um questionário estruturado na forma de uma escala Likert. A amostra da pesquisa compreendeu todas as universidades federais e estaduais que possuem e curso de Ciências Contábeis e todas as empresas de auditoria cadastradas no banco de dados da Comissão de Valores Mobiliários (CVM). As respostas obtidas foram tratadas por meio dos testes não paramétricos de Mann-Whitney e a Correlação de Spearman. Os resultados demonstram, que em, aproximadamente, $75 \%$ dos assuntos levantados neste trabalho, a academia tende a corresponder à expectativa que o mercado possui acerca da importância dada a tais conteúdos dentro da disciplina de auditoria. As principais diferenças encontradas dizem respeito a assuntos relacionados ao Assurance Service, Auditoria de Entidades sem Fins Lucrativos, Auditoria de Órgãos Governamentais, Controle de Qualidade e Auditoria de Sistemas de Informação, os quais não recebem a ênfase dentro da academia, de acordo com a perspectiva do mercado. Os resultados aqui apresentados podem ser utilizados para que os professores avaliem a disposição dos conteúdos abordados dentro da disciplina, considerando a relevância atribuída pelo mercado.
\end{abstract}

Palavras-Chave: Ensino. Auditoria. Tópicos de Auditoria.

\author{
Jhonatan Hoff \\ Mestrando em Contabilidade pela \\ Universidade Federal de Santa Catarina \\ (UFSC). Contato: Universidade Federal de \\ Santa Catarina, Centro Socioeconômico, \\ Bloco F, Trindade, Florianópolis (SC), CEP: \\ 88040-970. \\ E-mail: jhonatanhoff@hotmail.com

\section{Luiz Alberton} \\ Doutor em Engenharia da Produção pela \\ Universidade Federal de Santa Catarina \\ (UFSC) e Professor da Universidade \\ Federal de Santa Catarina (UFSC). \\ Contato: Universidade Federal de Santa \\ Catarina, Campus Universitário, Centro \\ Socioeconômico, Bloco C, Trindade, \\ Florianópolis (SC), CEP: 88040-970. \\ E-mail: luiz.alberton@ufsc.br
}

\section{Rita de Cássia Correa Pepinelli Camargo}

Doutoranda em Contabilidade pela Universidade Federal de Santa Catarina (UFSC). Contato: Universidade Federal de Santa Catarina, Centro Socioeconômico, Bloco F, Trindade, Florianópolis (SC), CEP: 88040-970.

E-mail: ritapepinelli@hotmail.com 


\section{Introdução}

Os últimos anos foram representados pelo período mais dinâmico e turbulento da história da auditoria. A expansão dos mercados a níveis globais, somada a escândalos financeiros, os quais culminaram no fracasso da Enron e na derrocada da Arthur Andersen, além da aprovação da Lei Sarbanes-Oxley e da criação do Public Company Accounting Oversight Board (PCAOB), trouxeram mudanças substanciais na profissão do auditor. Posterior a tais eventos no contexto internacional, um novo padrão contábil passou a ser preconizado no Brasil a partir do advento da Lei n. ${ }^{\circ} 11.638 / 2007$, a qual versa sobre a adoção das Normas Internacionais de Contabilidade também conhecidas como International Financial Reporting Standards (IFRS), as quais conduzem a mudanças importantes quanto à mensuração, ao reconhecimento e à divulgação das operações realizadas pelas empresas (Nogueira Júnior, Jucá \& Macedo, 2010).

Com base nesses episódios, Castañeda, Carvalho \& Lisboa (2007) citam que a profissão de auditoria no Brasil se insere nesse contexto de convergência por meio do Conselho Federal de Contabilidade (CFC) e do Instituto dos Auditores Independentes do Brasil (Ibracon) em busca de um alinhamento, não somente no que diz respeito às IFRS, mas, principalmente, com as Normas Internacionais de Auditoria. Como resultado de tal processo, a tendência é de que a atividade de auditoria passe a acompanhar as tendências mundiais no sentido prático e normativo.

Indiretamente, tais modificações exercem um impacto no ensino de auditoria. Na mesma medida que a prática profissional busca evoluir para atender as demandas do mercado, o processo de ensino de auditoria precisa ser continuamente reavaliado, para que assim ele possa preparar adequadamente os futuros profissionais da área (Armitage, 2008). E é justamente nesse ponto que reside o maior desafio dos cursos de Ciências Contábeis - projetar os currículos e conteúdos de forma que esses atendam às necessidades e evoluções da profissão. Particularmente, no caso da auditoria, percebe-se a existência de uma lacuna entre o ensino e a prática (Dombrowski, Smith, \& Wood, 2013; Silva, 2008).

No que se refere às modificações no campo profissional, o ensino de auditoria permaneceu alheio às evoluções da economia, distanciando-se abruptamente das práticas do mercado, conforme assinalado por alguns autores, como Armitage (2008), Chaffey, Peursem e Low (2011), Dombrowski et al. (2013), Humphrey (2008), Johnson, Baird, Caster, Dilla, Earley e Louwers (2003), Madeira (2001) e Ricardino Filho (2002). No Brasil, o ensino de auditoria não passou por nenhuma atualização relevante nos últimos cinquenta anos, sendo que o crescimento da profissão na área não foi devidamente correspondido pelos cursos de Ciências Contábeis, conforme asseveram Madeira (2001) e Ricardino Filho (2002).

Apesar da importância da profissão, tendo em vista que será o auditor o responsável por assegurar a confiabilidade das demonstrações financeiras aos usuários da informação contábil, Silva (2008) e Armitage (2008) ressalvam que as pesquisas que buscam identificar o processo de ensino em auditoria ainda são incipientes, mesmo no âmbito internacional. No Brasil, os estudos na área preocuparam-se, principalmente, com a avaliação de aspectos curriculares e as perspectivas do mercado de trabalho, como, por exemplo, os trabalhos de Madeira (2001), Ricardinho Filho, (2002, 2003), Silva (2008) e Veiga, Borges e Amorim (2014).

Frente às crescentes exigências do mercado, surge a necessidade de que as instituições de ensino, responsáveis pela formação dos futuros auditores, sejam alvo de uma criteriosa análise, sobretudo em relação à avaliação do ensino, com vistas a mitigar as diferenças entre a academia e as expectativas do mercado (Silva, 2008; Machado, Machado \& Guerra, 2014).

Nesse sentido, levanta-se o seguinte questionamento: qual é a percepção dos docentes e dos profissionais da área acerca do ensino de auditoria? Frente a tal questionamento, este trabalho tem como objetivo identificar a percepção do ensino de auditoria, sob o enfoque da academia e do mercado de trabalho, com base na avaliação da importância dada por profissionais e docentes aos principais aspectos conceituais e normativos da área de auditoria. 
A justificativa do trabalho encontra-se na importância de avaliar o conteúdo do ensino em auditoria, levando em consideração aspectos acadêmicos e profissionais. A comparação entre as expectativas do mercado e de docentes da área de auditoria, partindo da importância atribuída a determinados temas por cada um dos grupos, permite que o docente possa reavaliar o processo de ensino, sob a ótica de professores e de profissionais da área, identificando, dessa forma, quais são os assuntos tidos como mais relevantes entre os dois grupos. Tal abordagem, ainda, permite que as mudanças ocorridas no mercado de trabalho sejam absorvidas pela academia. Ademais, a presente comparação ainda fornece bases para que em um período linear sejam identificadas tendências no ensino de auditoria, bem como apontar as necessidades do mercado consideradas pelos profissionais da área (Armitage, 2008; Chaffey et al., 2011).

Além desta breve introdução, faz-se a seguir a revisão da literatura em que são discutidos os conceitos fundamentais para o entendimento da pesquisa; são apresentados nas seções seguintes os procedimentos metodológicos e a descrição e análise dos dados; e por fim, as conclusões e recomendações para estudos futuros.

\section{Referencial Teórico}

\subsection{O mercado e o ensino de auditoria}

A expansão dos mercados em nível global, principalmente, a partir da década de 1990, iniciou um processo de mudança significativa na profissão de auditoria. Em um contexto globalizado, em que os investidores, os governos, os órgãos reguladores e outras partes interessadas exigem a divulgação de informações acuradas sobre as atividades realizadas pelas empresas, o escopo da auditoria extrapola a verificação das demonstrações contábeis de acordo com os princípios e normas previstos e passa a incorporar, além dessa, considerações sobre o desempenho, avaliação e gestão do risco, entre outros elementos (Johnson $e t$ al., 2003). Adicionalmente, a atuação do auditor ainda é entendida por Niyama, Moraes da Costa, Alves Dantas \& Ferreira Borges (2013) como fundamental para o funcionamento do mercado de capitais, em razão de oferecer a segurança sobre a fidedignidade das informações contábeis publicadas, contribuindo, assim, para um ambiente de maior confiança e credibilidade.

Somado as modificações nas relações empresariais, Armitage (2008) acrescenta que as principais mudanças no campo da auditoria surgiram com os escândalos financeiros no início dos anos 2000, os quais culminaram no fracasso da Enron e na derrocada da Arthur Andersen. Estes eventos suscitaram a criação da Lei Sarbanes-Oxley e do Public Company Accounting Oversight Board (PCAOB). Não obstante, no que se refere ao contexto brasileiro, um novo padrão contábil passou a ser preconizado a partir do advento da Lei n. ${ }^{\circ}$ 11.638/2007, a qual versa sobre a adoção das Normas Internacionais de Contabilidade também conhecidas como International Financial Reporting Standards (IFRS), as quais conduzem a mudanças importantes quanto à mensuração, ao reconhecimento e à divulgação das operações realizadas pelas empresas, principalmente, no que diz respeito aos aspectos ligados à: "(i) representação das demonstrações financeiras; e, (ii) essência econômica das transações como base de seu reconhecimento" (Nogueira Jr. et al., 2010, p. 6).

Nesse sentido, Castañeda et al. (2007) acrescentam que como resultado do processo de convergência, a atividade de auditoria no Brasil tende a convergir de acordo com os padrões internacionais. A auditoria brasileira se insere nesse contexto a partir de uma cooperação mútua entre o Conselho Federal de Contabilidade (CFC) e do Instituto dos Auditores Independentes do Brasil (Ibracon) e, principalmente, com a publicação das Normas Brasileiras de Contabilidade aplicadas à auditoria elaboradas de acordo com a sua equivalente internacional, emitida pelo International Federation of Accountants (Ifac), também conhecidas como as NBC TAs. 
Para Armitage (2008), tais mudanças no âmbito prático exercem impacto no ensino de auditoria. Na mesma medida que a prática profissional busca evoluir para atender as demandas do mercado, o processo de ensino precisa ser continuamente reavaliado, para que, assim, ele possa preparar adequadamente os futuros profissionais da área. Nesse sentido, Ricardino Filho (2002) destaca que para reduzir, a níveis aceitáveis, o risco de emitir opiniões inadequadas sobre as demonstrações contábeis sob exame, o desenvolvimento de ferramentas ou o entendimento das complexas relações empresariais não se faz suficiente, é preciso, primeiramente, que os profissionais sejam adequadamente preparados para a prática.

Frente a isso, Silva (2008) configura a universidade como uma instituição voltada para preparar futuros profissionais para o mercado de trabalho, sendo que a análise das mudanças que ocorrem a sua volta se tornam elemento indispensáveis na elaboração do projeto político-pedagógico, objetivando dessa maneira, formar profissionais de acordo com as exigências do mercado. Além disso, é importante que os cursos de Ciências Contábeis sejam capazes de formar profissionais aptos para interagir como agentes de mudança, em contínua evolução. E é justamente nesse ponto que reside o maior desafio dos cursos de Ciências Contábeis - projetar os currículos e conteúdos de forma que esses atendam às necessidades e evoluções da profissão.Desse modo, Armitage \& Poyzer (2010) argumentam que a responsabilidade em manter os currículos atualizados recai, principalmente, sobre os professores, os quais devem estar atentos às mudanças da profissão, a fim de incorporá-las no cronograma de aula. Não obstante, Siriwardane, Kin Hoi Hu \& Low (2014) argumentam que o sucesso no processo de formação consiste na compreensão acadêmica das necessidades do mercado.

Uma melhor compreensão de tais necessidades pode ser alcançada partindo da análise das informações apontadas sobre os profissionais atuantes no campo de auditoria sobre o conhecimento necessário para o exercício profissão. Consoante a isso, Humphrey (2008) enfatiza que, para o desenvolvimento do conhecimento em auditoria e para o avanço dos processos de ensino na área, pesquisadores e profissionais de auditoria devem trabalhar em conjunto para que tanto no âmbito teórico, quanto no prático fluam em único sentido. Entretanto, Chaffey et al. (2011) salientam que com demasiada frequência os profissionais são ignorados nas pesquisas.

Adicionalmente, Humphrey (2008), ao se referir ao contexto americano, considera como frustrante a pouca atenção dada por pesquisadores à lacuna existente entre o mercado de trabalho e o ensino de auditoria. $\mathrm{O}$ autor ainda ilustra que a investigação contemporânea em auditoria pode ser mais proveitosa, se focada diretamente sobre a compreensão da prática da auditoria e da influência das instituições reguladoras sobre a profissão. $\mathrm{O}$ autor argumenta a relutância dos investigadores em compreender a profissão sob uma dimensão mais crítica e menos quantitativa. Humphrey (2008) identifica que o campo científico na área tem se distanciado do entendimento do exercício a profissão. $\mathrm{O}$ autor argumenta que dentro da academia se sabe, relativamente, pouco sobre a prática, não obstante, a legitimidade do conhecimento em auditoria permanece pouco pesquisada. Para o autor, a maior dificuldade reside na aproximação da pesquisa com pontos específicos da prática.

O distanciamento entre a academia e o mercado de trabalho, no contexto da auditoria, já foi argumentado em trabalhos anteriores, como Armitage (2008), Chaffey et al. (2011), Dombrowski et al. (2013), Humphrey (2008), Johnson et al. (2003), Madeira (2001) e Ricardino Filho (2002, 2003). Especificamente, no contexto brasileiro, Madeira (2001) e Ricardino Filho (2002) asseveram que o ensino da auditoria no Brasil não passou por nenhuma atualização relevante nos últimos cinquenta anos, de forma que o ensino acadêmico tem se distanciado abruptamente das práticas do mercado, sendo que o crescimento da profissão na área de auditoria não foi devidamente correspondido pelos cursos de Ciências Contábeis.

Para o melhor entendimento, tanto da lacuna existente entre os dois contextos, quanto da precarização do ensino da auditoria citadas anteriormente, faz-se necessário discorrer sobre a contextualização curricular da disciplina de Auditoria dentro do curso de Ciências Contábeis, levando em consideração seu surgimento e as principais discussões a seu respeito. 


\subsection{Questões curriculares e pesquisas anteriores}

O surgimento da disciplina de Auditoria no Brasil remonta ao ano de 1945, conforme explica Silva (2008). O autor cita que a auditoria foi, inicialmente, inserida nos cursos de Ciências Contábeis por meio do Decreto-Lei n. ${ }^{0} 7.988$ no ano de 1945, a qual foi denominada disciplina de Revisões e Perícia Contábil. Somente em 1992, quando já denominada disciplina de Auditoria Contábil, a disciplina passou a ser classificada como de conhecimento obrigatório.

No contexto brasileiro, as instituições de ensino superior possuem autonomia, conforme as diretrizes curriculares dos cursos em Ciências Contábeis, para determinar o conteúdo a ser abordado em seus planos de ensino (Machado et al., 2014). A padronização curricular, para Madeira (2001), apresenta vantagens e desvantagens. Por um lado, currículos padronizados permitem que o ensino seja de certa forma, uniformizado, independente da instituição de ensino ou de sua localização. No entanto, a uniformidade por si só não é uma garantia de ensino ou sequer de aprendizado. $O$ autor assevera que, quando demasiadamente padronizados, os currículos acabam por engessar o processo de ensino, limitando as possibilidades dos docentes, inclusive no que diz respeito ao uso da criatividade.

É importante destacar que para Silva e Moreira (2008, p. 7), “o currículo não se constitui em um elemento neutro de transmissão desinteressada do conhecimento social. Antes, o currículo está implicado em relações de saber, transmite visões sociais particulares e interessadas, produz identidades individuais e sociais particulares". Dessa forma, os preparadores dos currículos devem encontrar, conforme Johnson et al. (2003), o equilíbrio entre o ensino, o desenvolvimento de competências e a construção da consciência profissional. Nesse sentido, Siriwardane et al. (2014) afirmam que a profissão de auditoria envolve um conjunto amplo de conhecimentos e competências, de forma que a formação dos futuros profissionais de auditoria não recaia exclusivamente nas universidades, sendo que as empresas de auditoria também possuem responsabilidade em desenvolver os conhecimentos, técnicas e competências dos auditores.

Quanto às competências comportamentais necessárias à maximização da eficiência e eficácia dos trabalhos realizados pelas empresas de auditoria, Camargo, Camargo, Dutra e Alberton (2014, p. 46) indicam que as competências atribuídas como mais importantes aos auditores variam, conforme o enquadramento funcional desses, sugerindo, assim, que essas "não são estáticas e que possivelmente as competências que são importantes no início da carreira do auditor podem ser substituídas por outras conforme esse profissional adquire mais experiência". Nessa perspectiva, depreende-se que "combinando as competências transmitidas pelas instituições formais e as habilidades adquiridas por sua prática profissional e por suas iniciativas pessoais, em matéria de formação, o indivíduo torna-se agente e principal construtor de sua qualificação", em que as universidades atuam como mediadoras em tal processo, no tocante ao incentivo à busca pelo conhecimento (Silva, 2008, p. 35).

No que concerne às questões relativas ao capital humano, incluindo o ensino e a formação de profissionais de auditoria, o Advisory Committee on the Auditing Profession (ACAP) elaborou, em 2008, um relatório fornecendo recomendações para a melhoria da profissão nos Estados Unidos. O comitê alerta que o vínculo entre a profissão e a academia é subdesenvolvido e recomenda a orientação dos currículos para o mercado, procurando evoluir continuamente para atender às necessidades da profissão. Adicionalmente, o comitê considera que a harmonia entre o ensino e a prática tem como consequência direta a melhoria da qualidade dos serviços de auditoria, uma vez que os novos profissionais estarão preparados para resolver problemas específicos da área.

Além do supracitado relatório, faz-se importante citar a criação do Intergovernmental Working Group of Experts on International Standards of Accounting and Reporting-ISAR ainda no ano de 1976, o qual tem como objetivo promover o fortalecimento da profissão contábil e, entre outros, discutir assuntos relativos à formação profissional (Silva, 2008). 
Em 2011, o ISAR, por meio da United Nations Conference on Trade and Development (UNCTAD), divulgou a revisão de uma proposta curricular elaborada para o ensino da Contabilidade, buscando a concepção de um currículo global, a fim de possibilitar, além da harmonização do ensino da contabilidade, a formação de profissionais aptos a atuarem em um contexto globalizado. A proposta curricular oferecida pelo UNCTAD (2011, p.80-86), em seu item 3.8, no que diz respeito ao ensino da auditoria, preconiza a seguinte estrutura, a qual é apresentada neste trabalho de forma sintética:

3.8.1 Natureza, finalidade e extensão da auditoria

3.8.2 Normas de Auditoria e Padrões Internacionais de Auditoria

3.8.3 Princípios e Conceitos Fundamentais de Auditoria

3.8.4 Estrutura Básica da Auditoria

3.8.5 Avaliação e Planejamento da Auditoria

3.8.6 Obtenção e Análise de Evidências

3.8.7 Realização da Auditoria

3.8.8 Estrutura do Relatório de Auditoria

3.8.9 Auditoria Interna-Objetivos e Funções

No tocante ao contexto brasileiro, a Fundação Brasileira de Contabilidade (FBC), com base na Portaria CFC n. ${ }^{\circ} 13 / 2006$, elaborou uma Proposta Nacional de Conteúdo para o curso de graduação em Ciências Contábeis, a qual, no que tange à auditoria, preconiza a seguinte ementa:

Conceitos Básicos de Auditoria; Normas Técnicas e Profissionais de Auditoria; Planejamento de Auditoria; Seleção da Amostra e Avaliação de Risco; Controle Interno; Papéis de Trabalho; Pareceres de Auditoria; Auditoria das Contas Patrimoniais; Auditoria das Contas de Resultado; Relatórios de Auditoria; Revisão pelos Pares (FBC, 2008, p.69).

Para Ricardino Filho (2002), os dispositivos legais e o pronunciamento de órgãos de classe sobre a estrutura curricular denotam a preocupação em assegurar que os cursos superiores em Ciências Contábeis sejam ministrados de forma que seu arcabouço tenha uma ligação inerente à atividade, uma vez que a formação em Contabilidade é uma das prerrogativas para exercício da profissão de auditoria.

Quanto à agravante a lacuna teórico-prática existente, Ricardino Filho (2002) caracteriza a situação do ensino em auditoria no Brasil como, no mínimo, preocupante. O autor pondera que as disciplinas de auditoria ainda não possuem o destaque apropriado dentro do curso de Contabilidade, da mesma forma que a maioria dos docentes responsáveis pela disciplina não possuem a formação mínima de mestrado ou doutorado.

Além do mais, Chaffey et al. (2011) acrescentam que, ignorando a natureza complexa de diversos assuntos do currículo de auditoria, muitos programas de Contabilidade oferecem apenas um módulo relativamente curto voltado ao ensino da auditoria. Além disso, não há um consenso claro quanto ao que se deve ser ensinado ou quanto aos métodos de ensino que se devem ser empregados, criando, dessa forma, grande desafio para o educador.

Na pesquisa realizada por Ricardino Filho (2002), a qual teve como objetivo identificar se o ensino da disciplina Auditoria nas instituições de ensino superior brasileiras, demonstram condições de cumprirem seu papel de pré-qualificar minimamente os futuros militantes da área para o desempenho de seu papel, quer profissional, quer social, revelou que os docentes responsáveis pela disciplina possuíam pouca ou nenhuma experiência no mercado e tampouco formação na área ou haviam concluído cursos de mestrado ou doutorado. Além do mais, o autor identificou que o material utilizado para o apoio da disciplina contemplava práticas defasadas desde a década de 1990, as quais abordam apenas, de forma superficial, assuntos relacionados às Normas Internacionais de Auditoria, conceitos fundamentais, como relevância, risco de auditoria e amostragem estatística. 
Buscando fazer um paralelo entre o ensino da auditoria dentro da academia e os cursos ministrados pelas principais empresas de auditoria em comparação a proposta curricular preconizada pelo ISAR, o autor encontrou evidências do descompasso existente entre a academia e o mercado. Entretanto, cabe ressaltar que nesse caso, as diferenças já são esperadas, uma vez que, enquanto as universidades estão voltadas ao ensino, em uma concepção mais abrangente, os treinamentos oferecidos pelas empresas de auditoria estão voltados especialmente ao lado tecnicista (Ricardino Filho, 2002).

No que diz respeito à averiguação da importância de temas específicos da disciplina de Auditoria, Armitage e Poyzer (2010) demonstram que os temas mais importantes para os professores são o risco de auditoria, a compreensão do controle interno, obtenção de evidências, entendimento das demonstrações financeiras e questões relacionadas à fraude. Enquanto, para os auditores, os resultados revelaram que os tópicos mais importantes são os riscos de auditoria, questões relacionadas à ética, à documentação de auditoria, à compreensão do controle interno e aos procedimentos analíticos.

Soares, Soares, Lanzarin e Casagrande (2012) identificaram que os conteúdos mais recorrentes nas ementas das disciplinas de Auditoria foram: "Conceitos Básicos de Auditoria" (100\%), "Procedimentos e Técnicas de Auditoria” (92\%), "Relatórios de Auditoria e Tipos de Auditoria”, com 88\% de ocorrência cada; e os conteúdos menos recorrentes foram "Erros e Fraudes" (21\%) e "Prática de Auditoria", com (25\%).

$\mathrm{Na}$ pesquisa de Silva (2008) o autor buscou analisar a percepção dos profissionais de auditoria quanto ao ensino de auditoria contábil nos cursos de graduação em Ciências Contábeis do Brasil, bem como avaliar o estágio atual quanto a sua adoção como disciplina específica nos cursos de graduação em Ciências Contábeis nas IES do Brasil. Os resultados trazidos pelo autor apresentam divergências entre as opiniões de professores e profissionais de auditoria, principalmente, no que diz respeito à distribuição do conteúdo da disciplina, exigência de pré-requisitos e experiência profissional do docente.

Como observado, não foram encontradas pesquisas no âmbito nacional que busquem avaliar conteúdo do ensino em auditoria, levando-se em consideração aspectos acadêmicos e profissionais, conforme abordagem proposta neste trabalho. Portanto, ressalta-se a necessidade de uma pesquisa que busque identificar as expectativas do mercado e de docentes da área de auditoria, com a finalidade de fornecer subsídios para que a academia possa reavaliar o processo de ensino, levando-se em consideração aspectos apontados como relevantes pelo mercado de trabalho.

\section{Procedimentos Metodológicos}

De acordo com os preceitos metodológicos de Gil (2002), esta pesquisa caracteriza-se quanto à abordagem ao problema como predominantemente quantitativa. Quanto aos objetivos, a pesquisa classifica-se como descritiva, pois buscou-se conhecer as opiniões de profissionais e docentes da área de auditoria acerca da importância dos conteúdos ministrados na disciplina de Auditoria. No que diz respeito aos procedimentos, esta pesquisa caracteriza-se como levantamento, pois questionou-se um grupo de professores e um grupo de profissionais da área, buscando tomar conhecimento sobre o problema estudado.

Este trabalho assemelha-se, em sua essência, ao estudo desenvolvido por Armitage (2010). Contudo para alcançar o objetivo proposto, elaborou-se, como instrumento de coleta de dados, um questionário baseado nos trabalhos de Armitage (2008), Armitage e Poyzer (2010), Silva (2008), nas propostas curriculares preconizadas pela United Nations Conference on Trade and Development (UNCTAD) (2011) e pela Fundação Brasileira de Contabilidade (2009), além das Normas Brasileiras de Contabilidade aplicadas à Auditoria Independente (NBC PA) e Normas Brasileiras de Contabilidade aplicadas à Auditoria (NBC TA) que foram elaboradas de acordo com a sua equivalente internacional emitida pelo Ifac, buscando, dessa forma, contemplar aspectos pedagógicos, conceituais, práticos e normativos. 
O questionário foi estruturado na forma de uma escala Likert de cinco pontos ( 1 "pouca ênfase" - 5 "Muita ênfase"), contendo 44 tópicos acerca do ensino da auditoria, os quais foram distribuídos em seis grupos: (i) Ensino de Conceitos Gerais de Auditoria; (ii) Avaliação e Planejamento de Auditoria; (iii) Obtenção e Análise de Evidências; (iv) Execução do Trabalho de Auditoria; (v) Relatório de Auditoria; e (vi) Outras Áreas de Auditoria. Em cada um dos grupos havia a opção "outros tópicos", caso o participante desejasse adicionar algum assunto não mencionado no questionário. O questionário também abordou questões relativas à formação e experiência profissional dos participantes. Também foi feita uma questão aberta, caso os respondentes tivessem interesse em manifestar outros aspectos relevantes que devem ser abordados pela disciplina de Auditoria e que não foram abordados no questionário.

Buscando identificar a percepção dos profissionais acerca da relevância de determinados assuntos no ensino de auditoria, foi solicitado aos auditores que atribuíssem à ênfase com a qual eles acreditavam que tais assuntos deveriam ser abordados na disciplina de auditoria. $\mathrm{O}$ mesmo questionamento foi feito, de forma muito semelhante, aos professores, contudo, solicitou-se que esses assinalassem os conteúdos apontados de acordo com a ênfase com que eles eram abordados durante a disciplina. Tanto o questionário enviado para os professores quanto para os auditores possibilitava aos respondentes que assinalassem a alternativa "O assunto não é abordado" e "O assunto não precisa ser abordado", respectivamente. Em tais situações, atribuiu-se o valor de zero para o tratamento estatístico dos dados.

Para identificar a percepção dos auditores, a amostra selecionada para a pesquisa compreende 376 empresas de auditoria cadastradas no banco de dados da Comissão de Valores Mobiliários (CVM). Quanto aos professores, restringiu-se a amostra apenas às universidades públicas federais e estaduais reconhecidas pelo Ministério da Educação (MEC) que oferecem o curso de Ciências Contábeis, totalizando uma amostra com 72 universidades.

O questionário foi enviado aos auditores utilizando os e-mails cadastrados no banco de dados da CVM, enquanto o questionário correspondente aos professores foi encaminhado ao e-mail da coordenação do curso cadastrado no site das universidades, solicitando que o questionário fosse encaminhado aos professores responsáveis pela disciplina de Auditoria. Quando o e-mail do professor da disciplina era disponibilizado, o questionário foi encaminhado diretamente a ele. Os contatos foram consultados no dia $1^{\circ}$ de junho de 2015 e os e-mails com o link da pesquisa foram encaminhados no dia 9 de junho de 2015 e reencaminhados no dia 22 de junho de 2015. Foram obtidas 13 respostas dos professores e 35 dos auditores, o que indica uma representatividade amostral de $18,05 \%$ e $9,30 \%$, respectivamente.

As respostas obtidas foram tratadas com auxílio do Microsoft Excel ${ }^{\circ}$ e do software estatístico SPSS . Para testar a normalidade dos dados procedeu-se o teste de Shapiro-Wilk o qual rejeitou a hipótese de normalidade. Frente a isso, utilizou-se os testes não paramétricos de Mann-Whitney e a correlação de Spearman para avaliar as diferenças entre as respostas obtidas pelos dois grupos.

\section{Análise dos Resultados}

O perfil dos respondentes caracteriza-se por $27(77 \%)$ auditores que trabalham em empresas de auditoria não Big Four; e 8 (23\%) que trabalham em empresas Big Four. Quanto aos professores, 11 (85\%) pertencem a universidades federais e $2(15 \%)$ a universidades estaduais. A maior parte dos docentes possui a formação mínima de Mestrado (38\%) e doutorado (46\%), enquanto o restante possui apenas graduação ou especialização (16\%). Ao contrário dos resultados apresentados por Ricardino Filho (2002), os docentes encarregados pela disciplina de auditoria, respondentes desta pesquisa, possuem em sua maioria mestrado e doutorado. Contudo, deve-se levar em consideração que tal constatação pode ser decorrente da amostra da pesquisa, que se limitou a universidades públicas federais e estaduais. 
Do ponto de vista dos auditores, a formação mínima para o exercício da docência em auditoria é o mestrado (54\%) ou, no mínimo, o nível de especialização (26\%). Os níveis de graduação e doutorado foram assinalados apenas por dois respondentes cada. Três auditores, que responderam a pesquisa (9\%), acreditam que os requisitos mínimos necessários para a docência na área advêm da prática de auditoria e não da academia. A maioria dos auditores (97\%), com exceção de apenas um, concordam que a formação dos professores que ministram a disciplina de Auditoria nos cursos de graduação de Ciências Contábeis deve ser obrigatoriamente em Contabilidade. Tal perspectiva é correspondida pelos acadêmicos participantes da pesquisa, uma vez que todos os professores que responderam a pesquisa possuem formação em Contabilidade.

Os auditores foram questionados sobre qual deveria ser a experiência profissional do professor responsável pela disciplina de Auditoria, quase todos os respondentes (34), ou seja, $97 \%$ concordaram que o ideal seria que esses possuíssem, ao menos, experiência em uma empresa de auditoria independente. Do lado acadêmico, constatou-se que todos os professores respondentes possuem experiência na área contábil, entretanto, apenas dois (15\%) atuaram como auditores independentes. Outros dois atuaram, exclusivamente, como contadores, enquanto os demais possuem experiência em controladoria e em departamentos de auditoria de empresas públicas e privadas.

A metodologia de ensino considerada pelos auditores como mais adequada envolve o conjunto de aulas expositivas, estudos de caso, resolução de exercícios e seminários. A mesma opinião foi compartilhada parcialmente pelos professores, os quais utilizam a união dessas metodologias como abordagem para desenvolvimento de suas aulas. Entretanto, percebeu-se que uma grande parcela desses faz tão somente o uso de aulas expositivas como abordagem para o processo de ensino e aprendizagem em auditoria.

Solicitou-se aos auditores que atribuíssem à ênfase que eles acreditam que deva ser dada aos assuntos relacionados ao ensino de conceitos gerais de auditoria abordados na disciplina. O mesmo questionamento foi feito de forma muito semelhante aos professores, contudo, solicitou-se que esses assinalassem os conteúdos apontados de acordo com a ênfase que é dada no conteúdo da disciplina.

A Tabela 1 evidência as percepções acerca dos assuntos relacionados ao ensino de conceitos gerais de auditoria por cada um dos grupos investigados.

Tabela 1

\section{Ensino de Conceitos Gerais de Auditoria}

\begin{tabular}{|c|c|c|c|c|c|c|c|c|}
\hline \multirow{2}{*}{ Assunto } & \multicolumn{3}{|c|}{ Auditores } & \multicolumn{3}{|c|}{ Professores } & \multirow{2}{*}{ DM } & \multirow{2}{*}{$\frac{\text { Mann Whitney }}{\text { Sig. }}$} \\
\hline & Ranking & Média & DP & Ranking & Média & DP & & \\
\hline Ceticismo Profissional & $5^{\circ}$ & 4,40 & 1,14 & $6^{\circ}$ & 4,231 & 1,01 & 0,17 & 0,404 \\
\hline Julgamento Profissional & $6^{\circ}$ & 4,37 & 1,14 & $7^{\circ}$ & 4,231 & 1,01 & 0,14 & 0,490 \\
\hline $\begin{array}{l}\text { Natureza, Finalidade e } \\
\text { Extensão da Auditoria }\end{array}$ & $2^{\circ}$ & 4,57 & 0,95 & $1^{\circ}$ & 4,769 & 0,44 & $-0,20$ & 0,862 \\
\hline $\begin{array}{l}\text { Normas de Auditoria e } \\
\text { Padrões Internacionais de } \\
\text { Auditoria }\end{array}$ & $3^{\circ}$ & 4,46 & 0,98 & $3^{\circ}$ & 4,692 & 0,63 & $-0,24$ & 0,520 \\
\hline Objetivos Gerais do Auditor & $8^{\circ}$ & 4,23 & 1,03 & $2^{\circ}$ & 4,769 & 0,60 & $-0,54$ & 0,600 \\
\hline $\begin{array}{l}\text { Princípios e Conceitos } \\
\text { Fundamentais de Auditoria }\end{array}$ & $4^{\circ}$ & 4,46 & 1,15 & $4^{\circ}$ & 4,538 & 0,66 & $-0,08$ & 0,639 \\
\hline Requisitos de Certificação & $9^{\circ}$ & 3,51 & 1,25 & $9^{\circ}$ & 3,692 & 1,03 & $-0,18$ & 0,771 \\
\hline Requisitos Éticos & $1^{\circ}$ & 4,63 & 0,55 & $5^{\circ}$ & 4,308 & 0,85 & 0,32 & 0,254 \\
\hline $\begin{array}{l}\text { Responsabilidade Legal dos } \\
\text { Auditores }\end{array}$ & $7^{\circ}$ & 4,26 & 0,89 & $8^{\circ}$ & 4,154 & 0,90 & 0,10 & 0,679 \\
\hline
\end{tabular}

Legenda: DP - Desvio Padrão; DM - Diferença de Média.

Fonte: dados da Pesquisa. 
Conforme é possível visualizar na Tabela 1, dentro deste tópico, o assunto considerado como mais relevante pelos auditores diz respeito aos "Requisitos Éticos". O mesmo item é considerado apenas como o quinto mais importante do ponto de vista dos docentes. Questões relacionadas à Ética também foram consideradas como um dos assuntos mais importantes a serem abordados em sala de aula, do ponto de vista dos auditores na pesquisa de Armitage (2008) e Armitage e Poyzer (2010). É importante destacar que o curso de Ciências Contábeis no Brasil possui a disciplina de Ética como componente curricular obrigatório. Não obstante, o currículo sugerido pela UNCTAD (2011) para o curso de Contabilidade, também cita a Ética como uma disciplina específica. Dessa maneira, mesmo que as diferenças entre as percepções dos docentes e profissionais a respeito de tal assunto não tenha se mostrado estatisticamente significante, conforme $o$ teste de Mann-Whitney, deve-se levar em consideração a possibilidade de que esse assunto não seja demasiadamente enfatizado dentro da disciplina de Auditoria frente ao fato da existência de uma disciplina especificamente voltada ao desenvolvimento da consciência ética e ao estímulo de práticas voltadas a mesma.

Quanto aos professores, constatou-se que dentro deste tópico, expõem com maior ênfase, assuntos relacionados à "Natureza, Finalidade e Extensão da Auditoria". Tanto os auditores quanto os professores atribuem o mesmo grau de importância a assuntos relacionados a "Normas de Auditoria e Padrões Internacionais de Auditoria", "Princípios e Conceitos Fundamentais de Auditoria" e "Requisitos de Certificação", sendo que ao último é atribuída a menor ênfase por ambos os grupos. Embora diferenças tenham sido constatadas nestes assuntos, nenhuma delas foi significativa, conforme o teste de Mann-Whitney.

A Tabela 2 apresenta as percepções dos auditores e professores sobre os assuntos relacionados à avaliação e planejamento da auditoria. Conforme observar-se na Tabela 2, enquanto os professores estão preocupados em enfatizar assuntos relacionados aos "Procedimentos Analíticos", o mesmo tema não é avaliado com a mesma importância pelos auditores.

Tabela 2

\section{Avaliação e Planejamento de Auditoria}

\begin{tabular}{|c|c|c|c|c|c|c|c|c|}
\hline \multirow{2}{*}{ Assunto } & \multicolumn{3}{|c|}{ Auditores } & \multicolumn{3}{|c|}{ Professores } & \multirow{2}{*}{ DM } & \multirow{2}{*}{$\frac{\text { Mann Whitney }}{\text { Sig }}$} \\
\hline & Ranking & Média & DP & Ranking & Média & DP & & \\
\hline Ambiente Propício à Fraude & $11^{\circ}$ & 3,83 & 1,25 & $6^{\circ}$ & 4,462 & 0,78 & $-0,63$ & $0,089 *$ \\
\hline $\begin{array}{l}\text { Análise das Demonstrações } \\
\text { Financeiras }\end{array}$ & $6^{\circ}$ & 4,14 & 1,12 & $9^{\circ}$ & 4,000 & 1,00 & 0,14 & 0,564 \\
\hline Avaliação do Controle de Risco & $3^{\circ}$ & 4,26 & 1,01 & $4^{\circ}$ & 4,462 & 0,88 & $-0,20$ & 0,418 \\
\hline $\begin{array}{l}\text { Designação de Equipe Técnica e } \\
\text { Cronograma }\end{array}$ & $12^{\circ}$ & 3,80 & 1,05 & $12^{\circ}$ & 3,769 & 1,17 & 0,03 & 0,933 \\
\hline $\begin{array}{l}\text { Entendimento da Estrutura } \\
\text { Interna de Controle }\end{array}$ & $7^{\circ}$ & 4,14 & 1,06 & $2^{\circ}$ & 4,692 & 0,63 & $-0,55$ & $0,047 * \star$ \\
\hline Formas de Fraude & $10^{\circ}$ & 3,86 & 1,14 & $11^{\circ}$ & 3,923 & 1,50 & $-0,07$ & 0,575 \\
\hline $\begin{array}{l}\text { Materialidade no Planejamento } \\
\text { e na Execução da Auditoria }\end{array}$ & $2^{\circ}$ & 4,37 & 1,11 & $7^{\circ}$ & 4,385 & 0,77 & $-0,01$ & 0,572 \\
\hline Papéis de Trabalho & $8^{\circ}$ & 4,11 & 1,37 & $8^{\circ}$ & 4,308 & 0,95 & $-0,19$ & 0,949 \\
\hline $\begin{array}{l}\text { Planejamento da coleta de } \\
\text { evidências (amostragem de } \\
\text { auditoria) }\end{array}$ & $5^{\circ}$ & 4,17 & 1,12 & $5^{\circ}$ & 4,462 & 0,78 & $-0,29$ & 0,527 \\
\hline Procedimentos Analíticos & $4^{\circ}$ & 4,23 & 1,00 & $1^{\circ}$ & 4,692 & 0,63 & $-0,46$ & 0,110 \\
\hline $\begin{array}{l}\text { Responsabilidade do Auditor } \\
\text { em Relação à Fraude }\end{array}$ & $9^{\circ}$ & 4,06 & 0,94 & $10^{\circ}$ & 4,000 & 1,00 & 0,06 & 0,873 \\
\hline Risco de Auditoria & $1^{\circ}$ & 4,43 & 1,09 & $3^{\circ}$ & 4,538 & 0,88 & $-0,11$ & 0,606 \\
\hline
\end{tabular}

Legenda: DP - Desvio Padrão; DM - Diferença de Média.

Nota: *,** Significante a $10 \%$ e $5 \%$, respectivamente.

Fonte: dados da Pesquisa. 
Ainda de acordo com a Tabela 2, os assuntos relacionados a "Formas de Fraude" e a "Responsabilidade do Auditor em Relação à Fraude" foram assinalados com graus semelhantes de importância. Da mesma forma, percebe-se a concordância por ambos os grupos na relevância de temas relacionados a "Planejamento da Coleta de Evidências" e "Designação de Equipe Técnica" e "Cronograma".

Foram identificadas divergências significativas na importância atribuída ao "Entendimento da Estrutura Interna de Controle" (Tabela 2,), o qual é abordado com maior ênfase na disciplina, enquanto o assunto não é visto com tanta importância pelos auditores. Semelhante aos resultados encontrados pelo presente estudo, Armitage e Poyzer (2010) constatam a mesma divergência quanto à importância atribuída por profissionais e professores ao "Entendimento da Estrutura Interna de Controle" no contexto americano.

Por outro lado, pode-se perceber ainda diferenças significativas, no que diz respeito ao entendimento do "Ambiente Propício a Fraude", cujo assunto, apesar de ser o sexto mais enfatizado pelos professores dentro deste tópico, não é visto com a mesma importância por parte dos auditores. A maior relevância atribuída ao entendimento do "Ambiente Propício a Fraude" por parte dos professores, também foi identificada por Armitage e Poyzer (2010), os quais consideram que tal divergência corrobora a indicação de que a academia se preocupa com que o aluno entenda a forma com que o ambiente organizacional contribui para o processo fraudulento, fornecendo, assim, bases para o aperfeiçoamento de técnicas de detecção de fraude.

Na Tabela 3, pode-se visualizar as percepções dos auditores e professores sobre os assuntos relacionados à "Obtenção e Análise de Evidências".

Tabela 3

Obtenção e Análise de Evidências

\begin{tabular}{|c|c|c|c|c|c|c|c|c|}
\hline \multirow{2}{*}{ Assunto } & \multicolumn{3}{|c|}{ Auditores } & \multicolumn{3}{|c|}{ Professores } & \multirow{2}{*}{ DM } & \multirow{2}{*}{$\begin{array}{c}\text { Mann Whitney } \\
\text { Sig. }\end{array}$} \\
\hline & Ranking & Média & DP & Ranking & Média & DP & & \\
\hline $\begin{array}{l}\text { Evidência de Auditoria } \\
\text { Apropriada e Suficiente }\end{array}$ & $1^{\circ}$ & 4,26 & 0,98 & $1^{\circ}$ & 4,385 & 0,96 & $-0,13$ & 0,642 \\
\hline Tipos e Formas de Evidências & $2^{\circ}$ & 4,23 & 0,88 & $2^{\circ}$ & 4,308 & 0,85 & $-0,08$ & 0,791 \\
\hline Métodos de Amostragem & $3^{\circ}$ & 4,00 & 0,91 & $3^{\circ}$ & 3,923 & 1,19 & 0,08 & 0,931 \\
\hline Amostra Probabilística & $4^{\circ}$ & 3,77 & 1,11 & $4^{\circ}$ & 3,846 & 1,14 & $-0,07$ & 0,865 \\
\hline Amostragem Não Estatística & $5^{\circ}$ & 3,66 & 1,11 & $5^{\circ}$ & 3,846 & 1,14 & $-0,19$ & 0,620 \\
\hline
\end{tabular}

Legenda: DP - Desvio Padrão; DM - Diferença de Média.

Fonte: dados da Pesquisa.

No que diz respeito à expectativa dos profissionais da área em contrapartida com a ênfase em que tópicos relacionados à "Obtenção e Análise de Evidências", são abordados em aula, pode-se ver, conforme exposto na Tabela 3, que não foram verificadas diferenças significativas entre os grupos. Os dados apresentados na Tabela 3 demonstram um consenso, tanto do ponto de vista acadêmico, quanto do ponto de vista profissional, no que diz respeito a assuntos relacionados ao referido tópico, considerando que ambos os grupos atribuíram um grau de importância semelhante para cada item. É possível verificar que no que concerne à obtenção e análise de evidências, aos assuntos relacionados à Evidência de Auditoria Apropriada e Suficiente e Tipos e Formas de Evidências são avaliados como os assuntos que merecem maior atenção dentro da disciplina.

A Tabela 4, a qual demonstra a percepção dos auditores quanto à importância da abordagem de assuntos relacionados à "Execução do Trabalho de Auditoria" em comparação à profundidade que tais assuntos são abordados durante a disciplina de auditoria. 
Tabela 4

Execução do Trabalho de Auditoria

\begin{tabular}{|c|c|c|c|c|c|c|c|c|}
\hline \multirow{2}{*}{ Assunto } & \multicolumn{3}{|c|}{ Auditores } & \multicolumn{3}{|c|}{ Professores } & \multirow{2}{*}{ DM } & \multirow{2}{*}{$\begin{array}{c}\text { Mann Whitney } \\
\text { Sig. }\end{array}$} \\
\hline & Ranking & Média & DP & Ranking & Média & DP & & \\
\hline Papéis de Trabalho & $2^{\circ}$ & 4,11 & 1,13 & $1^{\circ}$ & 4,385 & 0,87 & $-0,27$ & 0,486 \\
\hline $\begin{array}{l}\text { Organização do Trabalho de } \\
\text { auditoria }\end{array}$ & $4^{\circ}$ & 4,06 & 0,94 & $2^{\circ}$ & 4,077 & 0,64 & $-0,02$ & 0,853 \\
\hline Continuidade Operacional & $3^{\circ}$ & 4,06 & 0,94 & $3^{\circ}$ & 3,769 & 1,09 & 0,29 & 0,405 \\
\hline Trabalhos Iniciais - Saldos Iniciais & $6^{\circ}$ & 3,97 & 0,98 & $4^{\circ}$ & 3,769 & 1,17 & 0,20 & 0,599 \\
\hline Revisão de Eventos Subsequentes & $8^{\circ}$ & 3,89 & 1,11 & $5^{\circ}$ & 3,692 & 1,60 & 0,19 & 0,971 \\
\hline Partes Relacionadas & $5^{\circ}$ & 4,00 & 1,08 & $6^{\circ}$ & 3,308 & 1,75 & 0,69 & 0,247 \\
\hline Representações Formais & $7^{\circ}$ & 3,97 & 0,95 & $7^{\circ}$ & 3,308 & 1,38 & 0,66 & 0,117 \\
\hline Controle de Qualidade & $1^{\circ}$ & 4,14 & 1,00 & $8^{\circ}$ & 3,231 & 1,42 & 0,91 & $0,032 * \star$ \\
\hline $\begin{array}{l}\text { Auditoria de Sistemas de } \\
\text { Informação }\end{array}$ & $9^{\circ}$ & 3,74 & 1,22 & $9^{\circ}$ & 2,308 & 1,84 & 1,44 & $0,010 * *$ \\
\hline
\end{tabular}

Legenda: DP - Desvio Padrão; DM - Diferença de Média.

Nota: ** Significante a 5\%.

Fonte: dados da Pesquisa.

Como constatado na Tabela 4, diferenças significativas foram encontradas na perspectiva de temas relacionados ao "Controle de Qualidade" e "Auditoria de Sistemas de Informação", visto que os p-value desses itens é inferior a 0,05, rejeitando, dessa forma, a hipótese de que tais itens sejam vistos com a mesma importância pelos grupos investigados.

Apesar de o item relacionado à "Auditoria de Sistemas de Informação" ter ocupado a mesma posição no ranking pelos dois grupos, percebe-se que essa temática é subavaliada por parte da academia, ou seja, enquanto os auditores tendem a atribuir a necessidade de maior aprofundamento desse conteúdo, a mesma opinião não é partilhada pelos professores, os quais não dedicam maior ênfase para esse tópico. Um possível motivo para tal diferença é explicado por Ricardino Filho (2003), o qual, ao analisar a bibliografia adotada dentro da disciplina de auditoria, constatou que os livros utilizados pelos professores remontam a década de 1990 e não abordam assuntos relacionados a sistemas de informação.

A opinião dos grupos sobre a abordagem de assuntos relacionados ao Relatório de Auditoria é apresentada na Tabela 5 .

Tabela 5

Relatório de Auditoria

\begin{tabular}{|c|c|c|c|c|c|c|c|c|}
\hline \multirow{2}{*}{ Assunto } & \multicolumn{3}{|c|}{ Auditores } & \multicolumn{3}{|c|}{ Professores } & \multirow{2}{*}{ DM } & \multirow{2}{*}{$\frac{\text { Mann Whitney }}{\text { Sig. }}$} \\
\hline & Ranking & Média & DP & Ranking & Média & DP & & \\
\hline Estrutura do Relatório de Auditoria & $1^{\circ}$ & 4,20 & 1,13 & $1^{\circ}$ & 4,923 & 0,28 & $-0,72$ & $0,014^{* *}$ \\
\hline $\begin{array}{l}\text { Recomendações a Política de } \\
\text { Gestão da Empresa }\end{array}$ & $3^{\circ}$ & 4,03 & 1,12 & $3^{\circ}$ & 3,231 & 1,64 & 0,80 & $0,098 *$ \\
\hline Relatório sobre o Controle Interno & $2^{\circ}$ & 4,03 & 1,07 & $2^{\circ}$ & 3,769 & 1,01 & 0,26 & 0,353 \\
\hline
\end{tabular}

Legenda: DP - Desvio Padrão; DM - Diferença de Média.

Nota: *,** Significante a $10 \%$ e $5 \%$, respectivamente.

Fonte: dados da Pesquisa. 
Conforme apresenta a Tabela 5, mesmo que os itens tenham recebido a mesma classificação entre os grupos dentro do ranking, percebe-se que a ênfase com que os assuntos relacionados à "Estrutura do Relatório de Auditoria" e "Recomendações a Política de Gestão da Empresa" são abordados em aula, difere-se, significativamente, da ênfase com que os auditores acreditam que tal assunto mereça ser debatido. Percebe-se que a "Estrutura do Relatório de Auditoria" é visto com maior importância por parte dos professores, enquanto é atribuída uma importância significativamente maior as "Recomendações a Política de Gestão da Empresa", por parte dos auditores.

No tocante à importância identificada por auditores em relação à abordagem de outras áreas de auditoria dentro da disciplina de Auditoria, verificou-se diferenças significativas entre as expectativas do mercado e o enfoque de tais assuntos dentro da academia, como pode ser visto na Tabela 6 .

Tabela 6

Outras Áreas de Auditoria

\begin{tabular}{|c|c|c|c|c|c|c|c|c|}
\hline \multirow{2}{*}{ Assunto } & \multicolumn{3}{|c|}{ Auditores } & \multicolumn{3}{|c|}{ Professores } & \multirow{2}{*}{ DM } & \multirow{2}{*}{$\begin{array}{l}\text { Mann Whitney } \\
\text { Sig. }\end{array}$} \\
\hline & Ranking & Média & DP & Ranking & Média & DP & & \\
\hline Assurance Services & $1^{\circ}$ & 3,77 & 1,19 & $1^{\circ}$ & 2,231 & 2,01 & 1,54 & 0,014 ** \\
\hline $\begin{array}{l}\text { Auditoria de Entidades sem Fins } \\
\text { Lucrativos }\end{array}$ & $2^{\circ}$ & 3,74 & 1,09 & $2^{\circ}$ & 1,846 & 1,68 & 1,90 & $0,001 * * *$ \\
\hline $\begin{array}{l}\text { Auditoria de Órgãos } \\
\text { Governamentais }\end{array}$ & $3^{\circ}$ & 3,71 & 1,07 & $3^{\circ}$ & 2,077 & 1,55 & 1,64 & $0,001 * * *$ \\
\hline
\end{tabular}

Legenda: DP - Desvio Padrão; DM - Diferença de Média.

Nota: $* *, * *$ Significante a $5 \%$ e $1 \%$, respectivamente.

Fonte: dados da Pesquisa.

Com base nos resultados demonstrados na Tabela 6, constata-se que o grupo dos auditores tende a dar mais importância à abordagem de assuntos relacionados à Assurance Services, Auditoria de Entidades sem Fins Lucrativos e Auditoria de Órgãos Governamentais. Por outro lado, tais temas não são tratados com a mesma relevância dentro das universidades, dado que os assuntos referenciados nesse tópico receberam uma avaliação de importância muito inferior, por parte dos professores, quando se comparado aos auditores. A importância atribuída a esses itens deixa margem ao entendimento de que eles são abordados de forma periférica dentro da disciplina de Auditoria ou, ainda, em muitas vezes, nem mesmo são levantados em aula. Percebe-se nesse campo, que a academia não corresponde às expectativas do mercado, quanto ao aprimoramento de assuntos voltados a outras áreas de auditoria.

As respostas obtidas pelos dois questionários, foram submetidas ao teste de correlação de Spearman, para identificar a concordância entre os dois grupos acerca dos temas apontados no levantamento. $\mathrm{O}$ teste de Spearman apresentou uma correlação positiva e significativa entre os dois questionários ao nível tolerado de erro de 0,05 (coeficiente $=0,757, p=0,000$ ). Ou seja, em aproximadamente $75 \%$ dos conteúdos abordados no questionário, os professores tendem a enfatizá-los na mesma medida que os auditores acreditam que esses devam ser enfatizados dentro da disciplina de Auditoria, demonstrando, dessa forma, a existência de certa concordância quanto aos assuntos mais importantes na disciplina de Auditoria. 
Na sequência, a pesquisa buscou identificar opiniões pessoais de cada um dos respondentes acerca do ensino de Auditoria, por meio de uma questão aberta. Por parte dos professores, inicialmente, os depoimentos apontam problemas relacionados à carga horária da disciplina, a qual não dispõe de tempo suficiente para o devido aprofundamento nas questões mais relevantes da área de auditoria, tampouco possibilita a contextualização teórico-prática, considerada, por alguns dos professores respondentes, como fundamental. Não obstante, os auditores argumentam que no vasto campo de atuação da auditoria, o ensino desse ramo do conhecimento dentro da universidade limita-se a uma contextualização mais genérica e superficial. A pesquisa de Silva (2008) identificou que a carga horária média da disciplina é de 86 horas/aulas, contudo, o autor considera que o ideal para o aprendizado seria uma carga horária média de 190 horas/aulas. Além de Silva (2008), os trabalhos de Chaffey et al. (2011) e Ricardino Filho (2002) já haviam levantado preocupações acerca da carga horária da disciplina, a qual está muito abaixo do mínimo necessário para a devida abordagem dos temas requeridos pela área.

A preocupação com a abordagem prática dos conhecimentos em auditoria fica evidente nas contribuições feitas pelos auditores, os quais elegem requisitos técnicos como essenciais dentro da grade curricular da disciplina de Auditoria. Contrapondo tal posicionamento, a colaboração deixada pelos professores deixa implícita a preocupação em oferecer direcionamentos teórico-práticos que possibilitem a resolução de problemas eminentes no cotidiano empresarial, que vão além da operacionalização de técnicas. Adicionalmente, foram apontados pelos professores o uso de debates em forma de seminário sobre a produção científica em auditoria como metodologia de ensino.

Os auditores respondentes ainda levantaram a necessidade do enfoque sobre o ambiente de Auditoria Independente no Brasil e no mundo, envolvendo questões relacionadas à estrutura organizacional e ao seu funcionamento. Do ponto de vista dos professores, além dos elementos levantados pelos auditores, os docentes consideram, também, importante à abordagem sobre antecedentes históricos da auditoria, tanto no Brasil como no contexto mundial, além da discussão de escândalos corporativos que foram deflagrados nos últimos anos. Frente a isso, alguns auditores, ainda, enfatizam a relevância de se abordar temas como "Compliance" e "Due Dilligence", além de um maior aprofundamento nas normas NBC TA e PA. Os auditores ainda levantaram a importância da discussão acerca do Princípio da Independência dentro da disciplina de Auditoria, sendo esse considerado, pelos auditores, como um princípio fundamental para o exercício da profissão de auditoria.

\section{Conclusões}

O objetivo deste trabalho foi identificar a percepção do ensino de Auditoria, sob o enfoque da academia e do mercado de trabalho, com base na avaliação da importância dada por profissionais e docentes aos principais aspectos conceituais e normativos da área de auditoria. Para alcançar o objetivo proposto, foi enviado um questionário aos docentes responsáveis pela disciplina de auditoria e aos auditores atuantes no mercado de trabalho. Os resultados demonstram que em, aproximadamente, $75 \%$ dos assuntos levantados neste estudo, a universidade tende a corresponder a expectativa que o mercado possui acerca da importância dada a tais conteúdos dentro da disciplina de auditoria. 
As diferenças mais significativas percebidas entre a opinião dos grupos referem-se principalmente a assuntos ligados ao "Assurance Service", à "Auditoria de Entidade sem Fins Lucrativos", à "Auditoria de Órgãos Governamentais", ao "Controle de Qualidade", à "Auditoria de Sistemas de Informação" e, à "Recomendações a Política de Gestão da Empresa" os quais o mercado acredita que deveriam ser mais enfatizados dentro da disciplina de auditoria do que de fato são. Por outro lado, professores tendem a atribuir maior importância a assuntos relacionados à "Estrutura do Relatório de Auditoria", ao "Entendimento da Estrutura Interna de Controle" e ao "Ambiente Propício à Fraude" do que o mercado acredita ser realmente necessário.

Os resultados ainda indicam que os professores enfrentam problemas relativos à carga horária da disciplina, impossibilitando, dessa maneira, o devido aprofundamento nos conteúdos necessários ao exercício da prática de auditoria, tampouco possibilita que o docente aborde a tão desejada contextualização teórico-prática, limitando o ensino da auditoria a uma visão mais generalista e superficial. Chaffey et al. (2011), Silva (2008) e Ricardino Filho (2002) já haviam levantado preocupações acerca da carga horária da disciplina, a qual está muito abaixo do mínimo necessário para a devida abordagem dos temas requeridos pela área.

Percebeu-se uma evolução no que diz respeito à qualificação do corpo docente da disciplina de auditoria, quando se comparado aos resultados da pesquisa de Ricardino Filho (2002), o qual identificou que, apenas uma pequena parcela dos docentes encarregados pela disciplina possuíam mestrado ou doutorado. Os respondentes desta pesquisa possuem, em sua maioria, mestrado e doutorado e experiência no mercado de trabalho. Deve-se levar em consideração que tal constatação pode ser decorrente da amostra da pesquisa, que se limitou a universidades públicas federais e estaduais.

Os resultados aqui apontados demonstram certo nível de concordância a respeito da importância dos principais conteúdos da disciplina de Auditoria, tomando como base a visão do mercado em comparação a da academia. Contudo, não permitem avaliar a existência de lacunas entre as duas perspectivas, uma vez que a formação profissional envolve um processo muito mais amplo e complexo que a abordagem de conteúdos.

Entretanto, considerando as constantes mudanças nas exigências do mercado de trabalho e a carga horária limitada das disciplinas de Auditoria, os resultados aqui apresentados, podem ser utilizados para que os professores avaliem a disposição dos conteúdos abordados dentro da disciplina, bem como possam incorporar questões e exigências atuais, levando em conta a relevância atribuída a tais assuntos na formação do auditor do ponto de vista do mercado de trabalho.

Para trabalhos futuros, sugere-se a ampliação da amostra utilizada nesta pesquisa, bem como avaliar o conteúdo da disciplina de auditoria sobre outras perspectivas, como a visão dos egressos nos cursos de Ciências Contábeis que acabam de ingressar no mercado de trabalho, além da discussão dos métodos de ensino utilizados dentro da disciplina. Torna-se ainda interessante o debate sobre os conhecimentos práticos e pedagógicos desejados para o exercício da docência em auditoria. Além do mais, sugere-se que a lacuna existente entre as expectativas do mercado e a academia no que tange a disciplina de auditoria, seja avaliada pelo ponto de vista da metodologia da Aprendizagem Baseada em Problemas (Problem-Based Learning - PBL), buscando, dessa forma, a melhoria da disciplina de Auditoria. Não obstante, a discussão envolvendo assuntos relacionados à aproximação, entre os dois mundos, merece ser abordada mais detalhadamente, principalmente, buscando identificar em até que ponto tal harmonização é benéfica ao processo de ensino e aprendizagem. 


\section{Referências}

Armitage, J. (2008). Changes in the importance of topics in auditing education: 2000-2005. Managerial Auditing Journal, 23(9), pp. 935-959. doi:10.1108/02686900810908463

Armitage, J. \& Poyzer, J. K. (2010). Academicians' And Practitioners' Views On The Importance Of The Topical Content In The First Auditing Course. American Journal of Business Education (AJBE), 3(1), pp. 71-82. doi:10.19030/ajbe.v3i1.375

Camargo, R. D. C. C. P., Camargo, R. V. W., Dutra, M. H., \& Alberton, L. (2013). A percepção dos auditados em relação às competências comportamentais dos auditores Independentes: um estudo empírico na Região da Grande Florianópolis/SC. Revista de Contabilidade e Organizações, 7(18), pp.3747. doi:10.11606/rco.v7i18.55303

Castañeda, B. E. G., Carvalho, L. N. G., \& Lisboa, N. P. (2007). Comparação entre as Normas de Auditoria do Brasil e as Internacionais (IAASB). Revista Contemporânea de Contabilidade, 4(7), pp. 81-100.

Chaffey, J., Peursem, K. A., \& Low, M. (2011). Audit education for future professionals: Perceptions of New Zealand auditors. Accounting Education: an international journal, 20(2), pp. 153-185. doi:10. 1080/09639284.2011.557492

Dombrowski, R. F., Smith, K. J., \& Wood, B. G. (2013). Bridging the education-practice divide: The Salisbury University auditing internship program. Journal of Accounting Education, 31(1), pp. 84-106. doi:10.4236/ojacct.2016.51001

Fundação Brasileira de Contabilidade (2009). Proposta nacional de conteúdo para o curso de graduação em ciências contábeis ( $2^{\mathrm{a}}$ ed.). Carneiro, J. D. (coordenador). Brasília, DF, Brasil. Recuperado em 14 de julho de $2015 \mathrm{em}$ : http://portalcfc.org.br/wordpress/wp-content/uploads/2013/01/proposta.pdf

Gil, A. C. (2002). Como elaborar projetos de pesquisa (5a . ed.). São Paulo: Atlas.

Humphrey, C. Auditing research: a review across the disciplinary divide. Accounting, Auditing \& Accountability Journal, 2008, 21(2), pp. 170-203. doi: 10.1108/09513570810854392

Johnson, E. N., Baird, J., Caster, P., Dilla, W. N., Earley, C. E., \& Louwers, T. J. (2003). Challenges to audit education for the 21st century: A survey of curricula, course content, and delivery methods. Issues in Accounting Education, 18(3), pp. 241-263. doi:10.2308/iace.2003.18.3.241

Machado, L., Machado, M. R. R., \& Guerra, F. M. (2014). Formação do Auditor nas Instituições de Ensino Superior e a Capacitação Profissional nas Firmas de Auditoria. Revista de Contabilidade da $U F B A, 8(1)$, pp. 4-20.

Madeira, C. A. (2001). Avaliação do ensino de auditoria nos cursos de graduação em Ciências Contábeis: uma pesquisa exploratória. Dissertação de Mestrado, Faculdade de Ciências Econômicas de São Paulo da Fundação Escola de Comércio Álvares Penteado, São Paulo, SP, Brasil.

Niyama, J. K., Moraes da Costa, F., Alves Dantas, J., \& Ferreira Borges, E. (2013). Evolução da regulação da auditoria independente no Brasil: análise crítica, a partir da teoria da regulação. Advances in Scientific and Applied Accounting, 4(2), pp. 127-161.

Nogueira Júnior, E., Jucá, M. N., \& Macedo, M. (2010). O impacto da harmonização das práticas contábeis brasileiras às internacionais na relação entre o lucro líquido e o fluxo de caixa operacional. Revista Contabilidade Vista \& Revista. 23(1), pp. 47-74.

Conselho Federal de Contabilidade (2012). Normas Brasileiras de Contabilidade: NBC TA - de auditoria independente: NBC TA estrutura conceitual, NBC TA 200 a 810. (2012). Recuperado em 31 de maio, 2015, de http://portalcfc.org.br/wordpress/wp-content/uploads/2013/01/NBC_TA_AUDITORIA.pdf. 
Ricardino Filho, A. (2003). Algumas limitações do ensino de Auditoria nos cursos de ciências contábeis no Brasil. Anais Congresso USP de Contabilidade, São Paulo, SP, Brasil, 3.

Ricardinho Filho, A. A. (2002). Auditoria: ensino acadêmico X treinamento profissional. Tese de Doutorado, Faculdade de Economia, Administração e Contabilidade, Departamento de Contabilidade e Atuária, Universidade de São Paulo, São Paulo, SP, Brasil.

Silva, A. P. A. Percepção dos profissionais de auditoria quanto ao ensino de auditoria contábil nos cursos de graduação em ciências contábeis do Brasil.(2008). Dissertação de Mestrado, Pós-Graduação em Ciências Contábeis, Universidade de Brasília/UFPB/UFPE/UFRN, Brasília, DF, Brasil.

Silva, T. T. \& Moreira, A. F. B. (2008). Currículo, cultura e sociedade (10ª ed.) São Paulo: Cortez.

Siriwardane, H. P., Kin Hoi Hu, B., \& Low, K. Y. (2014). Skills, Knowledge, and Attitudes Important for Present-Day Auditors. International Journal of Auditing,18(3), pp. 193-205. doi:10.1111/ijau.12023

Soares, S. V., Soares, J. G., Lanzarin, J., \& Casagrande, M. D. H. (2012). O Curso de Ciências Contábeis das Universidades Federais e a Auditoria: uma análise dos aspectos curriculares. Revista Cesumar - Ciências Humanas e Sociais Aplicadas, 17(1), pp. 1-17.

Treasury, U. S. (2008). Final Report of the Advisory Committee on the Auditing Profession to the US Department of the Treasury. The Department of the Treasury.

UNCTAD - United Nations Conference on Trade and Development (2011): Model Accounting Curriculum (Revised). Geneva, UNCTAD. Recuperado em 14 de maio de 2015 de: http://unctad.org/en/ PublicationsLibrary/diaemisc2011d1_en.pdf

Vasarhelyi, M. A., Teeter, R. A., \& Krahel, J. P. (2010). Audit education and the real-time economy. Issues in Accounting Education, 25(3), pp. 405-423. doi:10.2308/iace.2010.25.3.405

Veiga, R. M. B., Borges, L. J., \& Amorim, E. N. C. D. (2014). Profissão Auditor Independente no Brasil: percepção dos contadores registrados nos CRCs. Revista Catarinense Sa Ciência Contábil, 13(39), pp. 64-78. doi:10.16930/2237-7662/rccc.v13n39p64-78. 